\title{
Analysis on major drivers of cement consumption during the urbanization process in China
}

\author{
Zhi Cao ${ }^{\text {a, b }}$, Lei Shen ${ }^{\text {a, }}{ }^{\text {, }}$ Litao Liu ${ }^{\text {a, }}$, Shuai Zhong ${ }^{a}$ \\ a Institute of Geographic Sciences and Nature Resources Research (IGSNRR), CAS, 11A Datun Road, Chaoyang District, Beijing 100101, China \\ ${ }^{\mathrm{b}}$ University of Chinese Academy of Sciences, Beijing 100049, China
}

\section{A R T I C L E I N F O}

\section{Article history:}

Received 29 July 2015

Received in revised form

31 March 2016

Accepted 21 May 2016

Available online 28 May 2016

\section{Keywords:}

Cement consumption

Urbanization

Driving forces analysis

STIRPAT model

\begin{abstract}
A B S T R A C T
Accompanying by the rapid urbanization process of China, unprecedented amounts of cement have been poured into urban construction over the last decade. Since research is still scarce on the factors underlying the cement consumption, the motivation of this paper is to provide insight into cement-based socioeconomic metabolism and to improve understanding of the linkage between human activities and cement consumption. To explore the key impact factors of cement consumption, an extended STIRPAT model is exploited in this paper to examine the effect of population, Gross Domestic Product (GDP) per capita, cement consumption intensity, fixed investment and urbanization level with regional panel data of China from 2005 to 2013. The empirical results indicate that fixed investment and GDP per capita are the decisive driving factors of cement consumption. The unbalanced investment between infrastructure and people's livelihood reflects bias urbanization policy in China. Inverted-U shaped nexus between cement consumption and urbanization, as well as GDP per capita, are observed in the empirical results. Moreover, regional heterogeneities are taken into account in the model estimation. On the ground of the empirical findings, several policy recommendations are provided for policy makers. It is suggested that policy makers should take account of the regional discrepancy and implement a sustainable urbanization strategy to curtail cement consumption. Only when excessive fixed investment is curbed does the enthusiasm of cement consumption calm down.
\end{abstract}

() 2016 Elsevier Ltd. All rights reserved.

\section{Introduction}

Numerous local and global environmental issues that emerged in the 20th century are directly or indirectly related to the extraction of materials and evolutions in the magnitude and structure of socioeconomic metabolism (Krausmann et al., 2009). During the rapid urbanization progress, China is experiencing a transition stage from a predominantly agricultural economy to an industrybased economy and facing tremendous environmental challenges. Fast-growing urbanization in China, which is characterized by accelerated socioeconomic metabolism and city sprawl, has claimed for an unprecedented amount of cement products to construct and sustain buildings and infrastructures (HirschnitzGarbers et al., 2015). From 1978 to 2010, China's urban population has grown dramatically from 170 to 670 million while the urban share of the total population rose from a mere $18 \%-50 \%$ owing to

\footnotetext{
* Corresponding author. Tel.: +86 1064888073 13; fax: +86 1064889005 .

E-mail addresses: caozhi.14b@igsnrr.ac.cn (Z. Cao), shenl@igsnrr.ac.cn (L. Shen).
}

the economic reforms (Chen et al., 2013). The concomitant economic boom in the urbanization has also witnessed an enormous amount of cement consumption (Woodward and Duffy, 2011). As an important barometer of general socioeconomic activities (Shen et al., 2014), cement plays a fundamental role in building and infrastructure sectors (Rodrigues and Joekes, 2011). During the period 1978 to 2010, China's cement consumption and cementrelated carbon emission grew from 65.24 to $1879.19 \mathrm{Mt}$ and 8.87 to $255.68 \mathrm{Mt}$, respectively (CCA, 2012). In the perspective of the socioeconomic metabolism, the cement inflow (i.e. cement consumption) within the socioeconomic system can be considered as one of the indicators of how human activities exploit resources and affect the environment. Due to the energy-intensive and materialintensive characteristic of cement products, the consumption of cement during the urbanization is blamed for anthropogenic environment impact, either for unsustainable resource use (Zhu et al., 2014) or greenhouse gases (GHG) emissions (Ali et al., 2011). Apparently, if the construction and economic development continue in an extensive mode, China will inevitably face a shortage of domestic resource supplies and environmental challenges (Shen 
et al., 2005). Since great cement consumption has induced serious resource and environmental challenge for sustainable development, it is imperative to curb excessive cement demand. To do it efficiently, the factors that have impact on the cement consumption and the extent of their influence are to be examined.

Previous scholars have employed material flow analysis (MFA) methodology to portray the material and energy flow of Chinese construction activities in the perspective of socioeconomic metabolism. Wang et al. (2016) presented a snapshot of country-wide cement and concrete material cycle in China based on general MFA method. Considering the time effect, dynamic MFA models were established to simulate the long-term evolution of building stock (Hu et al., 2010b), to estimate the history cement consumption and to forecast the future cement demand of building subsystem (Huang et al., 2013). In terms of city scale, cement consumption in residential building system (Hu et al., 2010a) and road system (Guo et al., 2014) were accounted as well. These cement-related MFA studies concentrated on the amount of material across different components in the socioeconomic system. Apparently, these material flow analyses can identify the quantity of cement throughput in the inflows of metabolism. However, they cannot discern the external driving forces that formulate the flow process from cement consumption to cement discards. The cement consumption level is determined exogenously and assumed to be saturated over time in these above literature.

Similar assumption is adopted in another strand of literature underpinned by prediction of cement consumption. For simplification, Lei et al. (2011) and Ke et al. (2012) adopted prediction outcomes from extant researches and set three stylized scenarios (high, medium and low) for future cement demand. On one hand, several scholars have applied linear regression model with a single explanatory variable to examine driving forces of China's cement consumption (Wang et al., 2014; Xu et al., 2014). On the other hand, unlike these models, Wen et al. (2015) posited that the Chinese cement demand is to follow a time-driven S-curve trend without considering socioeconomic factors. As observed in the above literature, factors influencing cement consumption are still unclear. It is verified that cement consumption is the most crucial factor for generating projections of cement-related environmental burden (Wang et al., 2013b; Xu et al., 2012). As can be seen, if the driving factors of cement consumption have not been explored in depth, this would lead to uncertainty for prediction of the cement consumption. Additionally, there exists spatial discrepancy of the driving forces that influence cement consumption in different regions. The nexus between driving forces and cement consumption in different regions, thereupon, should be investigated. For these reasons, a quantitative exploration of drivers related to cement consumption is urgent that can facilitate national decision makers and local urban planners to track cement consumption trend, to formulate management strategies and policies, and then to promote the development of resource-saving and environment-friendly city. Recently, the STIRPAT model has been extensively harnessed by researchers in economic environmental analysis for its extendibility (Fan et al., 2006; Ji and Chen, 2015; Jia et al., 2009; Lin et al., 2009; Liu et al., 2015; Shahbaz et al., 2016; Wang et al., 2013a). These studies, however, rarely concern about which factors are driving or reducing regional cement consumption in China. Nonetheless, previous researches can still provide solid bolster and useful enlightenment when determine the driving factors related to the cement consumption.

In this paper, an extended Stochastic Impacts by Regression on Population, Affluence, and Technology (STIRPAT) $1 \mathrm{~F}$ model is adopted to unravel the drivers of China's cement consumption volatility in the process of urbanization. Though there are applications with structural decomposition analysis (SDA)2F and
Logarithmic-Mean Divisia Index (LMDI)3F to examine the social and economic driving factors of the deteriorating environment issues occurred in China's urbanization process (Ang and Zhang, 2000; Guan et al., 2008; Liu et al., 2007; Xu et al., 2012; Zha et al., 2010). Instead, with the application of STIRPAT model, more detailed influence factors, even a non-monotonic or nonproportional function form, can be integrated into the regression model (Wang et al., 2013a). Moreover, with an adaption of quadratic terms of urbanization and affluence, this paper attempts to reveal the linear and nonlinear nexus between cement consumption and driving forces. On the basis of the empirical results, conclusions and policy implications are drawn.

\section{Methods}

A brief description of the STIRPAT model with extended variables is presented in this section, as well as definition of variables, specification of model and estimation methods.

\subsection{The STIRPAT model}

Dating back to the origin, STIRPAT model was derived from IPAT identity proposed in the early 70s by Ehrlich and Holdren (1971) and was reconceptualized by Waggoner and Ausubel (2002) as an ImPACT identity. To facilitate hypothesis testing, the identity was reformulated into a stochastic form (Dietz and Rosa, 1994) (Eq. (1)):

$I=a P^{b} A^{c} T^{d} e$

After converting all factors into a natural logarithm form, it is not difficult to determine the responsiveness and sensitivity of environmental impacts to a change in anyone of the driving forces using cross-sectional, time series or panel data (York et al., 2003). The modified model is presented below (Eq. (2)):

$\ln (I)=\ln a+b \ln (P)+\operatorname{cln}(A)+\operatorname{dln}(T)+\ln e$

where I denotes the environment impact; $P$ denotes population; $A$ presents affluence; $T$ refers to everything that is not population and affluence (including technology) and $e$ is the error term. The constant $a$ scales the model, $b, c$ and $d$ refer to the percentage change in environmental impact change caused by a $1 \%$ change in an impact factor while other factors are controlled, namely, ecological elasticity (EE).

York et al. (2003) also indicates that the STIRPAT model allows additional factors to be added to the basic STIRPAT as long as they are conceptually appropriate, which is very helpful to explicitly disaggregate driving forces behind the cement consumption or demand. Moreover, the regional characteristics, which cannot be conceptualized for multiplicative model, also can be indicated by a series of dummy coded (0-1) variables. Due to its flexibility, since then, various versions of extended STIRPAT models were formulated. Especially, consumption or emission intensity and urbanization level are the most frequently-used indicators of driving factors (Fan et al., 2006; York, 2007; Lin et al., 2009; Liddle and Lung, 2010; Wang et al., 2013a; Zhao et al., 2014).

\subsection{The driving factors}

According to the rule of thumb, population and affluence are exploited here as usual independent variables. In addition, urbanization level, fixed investment and cement consumption intensity are considered as contributory factors as well. 
(1) Population. Population growth will enlarge the requirement of residential construction areas, which directly results in the increased cement consumption.

(2) Urbanization level. Urbanization rate reflects the population structure of rural and urban. During the process of urbanization, the increase of productivity liberates the agrarian labor and assimilates 20 million new citizens annually (NBSC, 2014). Consequently, the accommodation of the growing population in the cities involves more intensive cement consumption.

(3) Fixed investment. To sustain the increasingly tremendous urban system, large amount of fixed investment has been poured into not only the residential blocks construction, but also the ancillary non-residential facilities, e.g., commercial buildings, industrial buildings and infrastructure construction. Infrastructure construction includes transportation, power generation and distribution networks (including dams for hydroelectric energy production and water collection) (Fernandez, 2007). The urbanization growth in recent decades is to a great extent benefited from huge infrastructure construction.

(4) Income level. As income level increases, people require more adequate living space in dwellings, because living space per capita is an indicator for social development (Müller, 2006). Rising living space claims for more cement inflow into the construction system.

(5) Cement consumption intensity. The change in architectural structure and the material content per unit of construction area both determine resources utilization efficiency. For instance, buildings with concrete structure have a larger amount of cement use in comparison to brick-wood structures (Hu et al., 2010a).

\subsection{Model specification}

The variable $T$ is disaggregated into three components: cement consumption intensity $(T)$, urbanization level $(U)$ and fixed investment $(F)$. To test the existence of an inverted-U shaped curve link between cement consumption and urbanization level or affluence, quadratic term of these two variables are added to the original model. Furthermore, regional and time dummies are introduced to capture the regional-specific or time-specific disturbance. All variables except urbanization level are transformed into natural logarithmic form. Then three reformulated cement-specific STIRPAT models are as follows (Eqs. (3)-(5)):

$$
\begin{aligned}
\ln C_{i, t}= & \ln a_{1}+a_{2} \ln P_{i, t}+a_{3} \ln A_{i, t}+a_{4} \ln T_{i, t}+a_{5} \ln F_{i, t}+a_{6} U_{i, t} \\
& + \text { Region }_{i}+t+e_{i, t}
\end{aligned}
$$

$$
\begin{aligned}
\ln C_{i, t}= & \operatorname{lna}_{1}+a_{2} \ln P_{i, t}+a_{3} \ln A_{i, t}+a_{4} \ln T_{i, t}+a_{5} \ln F_{i, t}+a_{6} U_{i, t} \\
& +a_{7} U_{i, t}^{2}+\operatorname{Region}_{i}+t+e_{i, t}
\end{aligned}
$$

$$
\begin{aligned}
\ln C_{i, t}= & \ln a_{1}+a_{2} \ln P_{i, t}+a_{3} \ln A_{i, t}+a_{8}\left(\ln A_{i, t}\right)^{2}+a_{4} \ln T_{i, t} \\
& +a_{5} \ln F_{i, t}+a_{6} U_{i, t}+\operatorname{Region}_{i}+t+e_{i, t}
\end{aligned}
$$

where the subscript $i$ denotes each area; $a_{1}$ presents the constant; $a_{2}, a_{3}, a_{4}, a_{5}$ and $a_{6}$ denote the EE of population $(P)$, Gross Domestic Product (GDP) per capita $(A)$, cement consumption intensity $(T)$, fixed investment $(F)$ and urbanization level $(U)$, respectively; $a_{7}$ and $a_{8}$ refer to semi-elasticity of the quadratic terms of urbanization level $(U)$ and GDP per capita $(A)$, respectively; $C_{i, t}$ presents the total cement consumption in a given region and unique time; Region $_{i}$ is the region-specific disturbance term (i.e., the regional-specific intercept term); $t$ is the time effect term, $e_{i, t}$ is the error term. Table 1 lists the definition of all variables.

Given the fact that cement products are too heavy to be transported in a long distance, cement is largely produced and consumed domestically within $300 \mathrm{~km}$ (Uwasu et al., 2012; Shen et al., 2014). Therefore, an aggregation of each province's output in a certain region, in some extent, can be considered as consumption of this region. Unlike the common economic development division in China, the consumption market of cement is divided into seven regions (Fig. 1): the northeast area (including the provinces: Heilongjiang, Jilin, Liaoning), the northern area (including the provinces: Inner Mongolia, Shanxi, Beijing, Hebei, Tianjin), the eastern area (including the provinces: Shanghai, Jiangsu, Zhejiang, Anhui, Jiangxi, Shandong), the central area (including the provinces: Henan, Hubei, Hunan), the southern area (including the provinces: Fujian, Guangdong, Guangxi, Hainan), the northwestern area (including the provinces: Shaanxi, Gansu, Qinghai, Ningxia, Xinjiang) and the southwestern area (including the provinces: Chongqing, Sichuan, Guizhou, Yunnan, Tibet). This division is based on the market characteristic of the cement industry in China (Uwasu et al., 2012; CLCRC, 2013).

\subsection{Estimation methods}

Since this research employs a long panel data, groupwise heteroskedasticity, autocorrelation and cross-sectional correlation should be considered, let alone the fixed effect. Hence, 4 estimation methods are conducted respectively to assess the effect of the above-mentioned variables on cement consumption.

Pooled OLS regression has omitted the individual heterogeneity. Firstly, to address the individual and time fixed effect of the panel data, fixed effect (FE) and two-way fixed effect (TW FE) regression are applied. The modified Wald test for groupwise heteroskedasticity (Greene, 2000) is used to test the groupwise heteroskedasticity in these two fixed effect model. Moreover, there exists autocorrelation using the Wooldridge test for autocorrelation in panel data model (Wooldridge, 2000). In addition, the results of Pesaran's (2004) test confirm the existence of cross-sectional dependence. Finally, a feasible generalized least squares regression method (FGLS) with cross-sectional correlation is taken to provide the soundest estimation for regression of socioeconomic activity on cement consumption. Table 2 presents the results of the hypothesis testing for autocorrelation, cross-sectional dependence and groupwise heteroskedasticity. The p-value of all testing is at the $10 \%$ level or lower, thereby null hypothesis is rejected.

\section{Data sources and descriptive analysis}

\subsection{Data sources}

In the absence of reliable statistical data of cement consumption, provincial cement outputs in a given region are aggregated as an approximation of consumption. Subsequently, every item of regional data is calculated by dividing 31 provincial data (except for Hongkong, Macao and Taiwan) into 7 regions, whereupon a balanced panel dataset of 7 areas is established. For instance, GDP per capita in the northeastern region is calculated by dividing total GDP of Heilongjiang, Jilin and Liaoning provinces by the combined population of these three provinces. Likewise, cement consumption intensity is computed by dividing total cement consumption by GDP. Moreover, to eliminate the price inflation or deflation, real 
Table 1

Definition of the variables used throughout this paper.

\begin{tabular}{|c|c|c|}
\hline Variable & Definition & Unit of measurement \\
\hline Population $(P)$ & Resident population living in urban area & 10000 \\
\hline GDP per capita $(A)$ & GDP divided by population & Yuan per capita (1993 prices) \\
\hline Cement consumption intensity $(T)$ & Cement consumption divided by GDP & 10000 tons per 100 million Yuan (1993 prices) \\
\hline Urbanization $(U)$ & The percentage of the urban population in the total resident population & Percent \\
\hline Fixed investment $(F)$ & Investment in fixed capital or depreciated fixed capital & 100 million Yuan (1993 prices) \\
\hline Regional dummy (Region) & Regional dummy variable & Region $=2, \ldots, 7$ \\
\hline Time trend $(t)$ & Time effect variable & $\mathrm{t}=1,2, \ldots 9$ \\
\hline Total cement consumption $(C)$ & Sum of cement consumption in a certain region & 10000 tons of cement \\
\hline
\end{tabular}

GDP is computed using the base year's prices (1993). All data used in this paper are obtained from the China Statistical Yearbook and National Bureau of Statistics of China (NBSC, 2014).

\subsection{Data description}

There exist significant disparities among these seven regions, with respect to their cement consumption and economic development. Fig. 2 (a) reflects that cement consumption increased during the period 2005-2013 in all regions. In 2005, the highest consumption quantity (eastern) was 7.4 times that of the lowest (northeastern). By 2013, each area's cement consumption, respectively, has been increased $15.59 \%$ (northeastern), 10.67\% (northern), 7.41\% (eastern), 18.45\% (central), 14.64\% (southern), 25.79\% (southwestern), and $31.27 \%$ (northwestern) annually. In comparison, Fig. 2 (b) represents clearly that the growth of population in seven regions is experiencing slower and smooth changes, increasing by an average rate of $0.6 \%$ per annum from 2005 to 2013 , respectively. Occasionally, the southwestern area is even experiencing a decline.

Fig. 2 (c) demonstrates that every region's GDP per person has been increasing rapidly on a steady upward trend by more than $15.14 \%$ per annum from 2005 to 2013 . Though there is a certain gap between developed regions and sub-developed regions in terms of GDP per capita, the affluence's growth rate of sub-developed areas is astonishing. Together with the sharp increase of affluence, total fixed investment of these seven regions has been enhanced by more than 147.83\% from 2005 to 2013 (Fig. 2 (d)).

As illustrated in Fig. 2 (f), the urbanization level of the northeastern region, eastern region, northern region and the southern region is remarkably higher than that of other regions. On the other hand, the urbanization level of the central region, southwestern region and northeastern region increase faster, improving at the pace of $3.73 \%, 3.98 \%$ and $3.42 \%$ every year, respectively. Over the

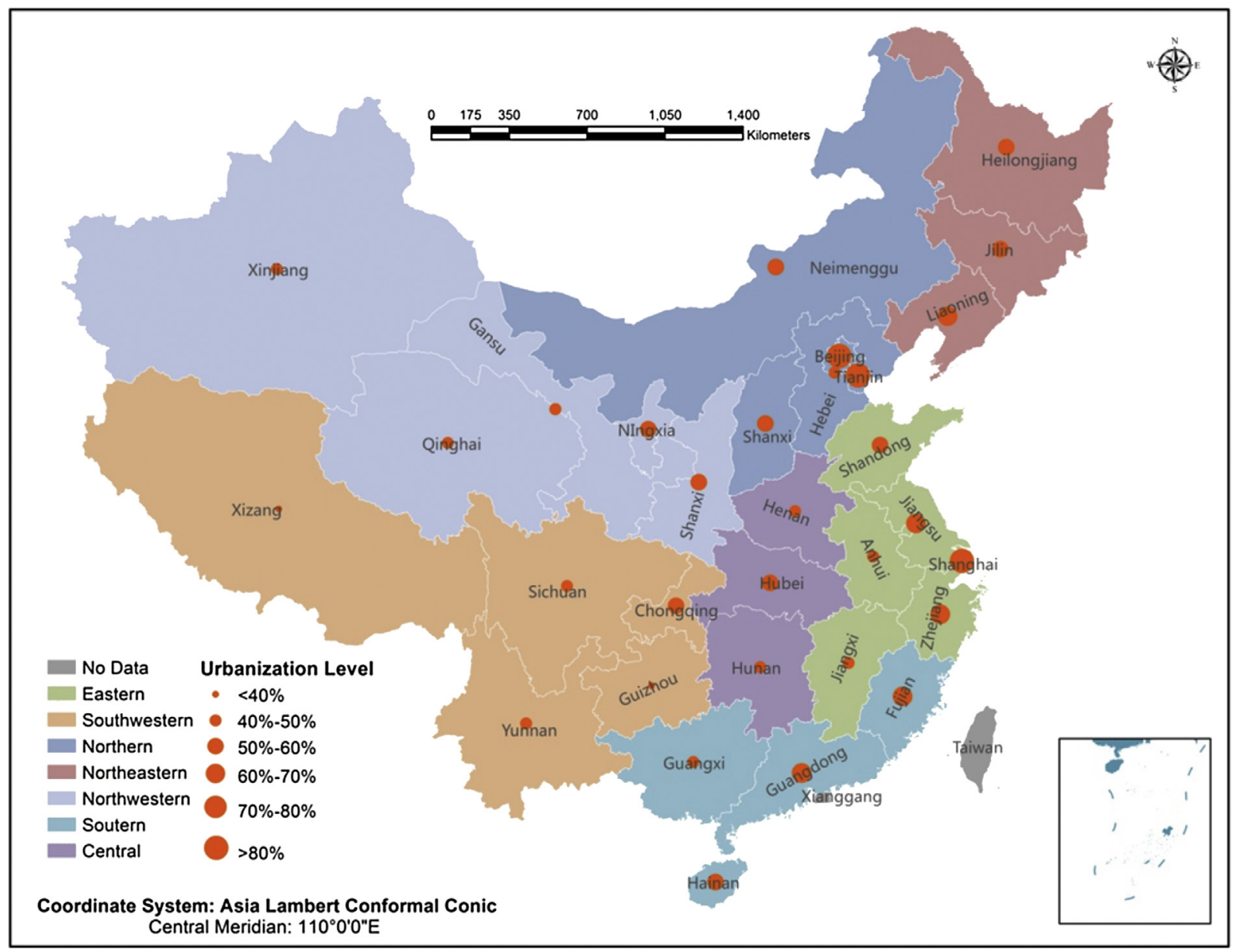

Fig. 1. Regional division of cement consumption and urbanization levels in 2013. 
Table 2

Hypothesis testing of autocorrelation, cross-sectional dependence and groupwise heteroskedasticity.

\begin{tabular}{|c|c|c|c|}
\hline Test typed & Eq. (3) & Eq. (4) & Eq. (5) \\
\hline Autocorrelation test & $F(1,6)=203.295^{* * *}$ & $F(1,6)=315.293^{* * *}$ & $F(1,6)=330.387^{* * *}$ \\
\hline Cross-sectional dependence test & $C D=1.872^{*}$ & $C D=2.086^{* *}$ & $C D=2.145^{* *}$ \\
\hline Groupwise Heteroskedasticity test & $\chi^{2}(7)=138.18^{* * *}$ & $\chi^{2}(7)=98.55^{* * *}$ & $\chi^{2}(7)=51.70^{* * *}$ \\
\hline
\end{tabular}

Note: ${ }^{*} \mathrm{p}<0.1,{ }^{* *} \mathrm{p}<0.05,{ }^{* * *} \mathrm{p}<0.01$.

period of 2005-2013, the cement consumption intensity has gone through a process of fluctuation and descent (Fig. 2 (e)). Cement consumption intensity of northwestern region has an overall upward trend and grows by $5.31 \%$ annually, followed by that of southwestern region with an annual growth of $2.50 \%$. The intensities of central region, southern region, and northeastern region remain in relatively stable level of $0.34 \%,-0.51 \%$, and $-0.60 \%$, respectively. Compared to the other regions, the cement consumption intensity of northern region and eastern region both display the diminishing trends, declining by $2.42 \%$ and $3.43 \%$, respectively. The apparent variation of cement consumption intensity reflects the development gaps between different regions. Nationally, concrete structures are substituting the wood-brick structures and other primitive structures (Wang et al., 2015a). Steel and steel reinforced concrete are gaining an increasing share of newly-built constructions in wealthier and densely populated regions while the brick concrete is still the mainstream in sub-developed regions, especially in the southwestern region and northeastern region.

The change in cement consumption coincides with parallel change in all variables except consumption intensity. The remainder of this paper aims to explore whether these variables affect cement consumption and contribution of these variables to cement consumption.

\section{Empirical results and discussion}

The results in Table 3 present the impact of population, affluence, technology, urbanization and fixed investment on cement consumption with 4 estimation methods, i.e., fixed effect (FE), twoway fixed effect (TW FE) and feasible generalized least squares regression without cross-section correlation (FGLS (1)) or with cross-section correlation (FGLS (2)). The estimation results arise from Eq. (3) serve to illustrate the linear effects of driving forces. The nonlinear effects of driving forces are illustrated by the results from Eq. (4) and Eq. (5). The relatively small standard errors of FGLS (2) imply more robust regression estimations. Thus, the effects of driving forces are interpreted based on this estimation method. The estimation results of all variables in FGLS (2) are significant at 5\% level or lower.

\subsection{Linear effects of driving factors}

The gap between regression results of fixed investment and urbanization is significant. Beyond expectation, urbanization has negligibly small positive influence on cement consumption compared to fixed investment. The regression coefficients of urbanization and fixed investment of Eq. (3) are 0.0445 and 0.6549 , respectively. That is to say a $1 \%$ increase in fixed investment would lead to $0.6549 \%$ increase in the cement consumption when other factors remain constant. Whereas, every 0.01 unit increase of urbanization will merely result in a $0.0445 \%$ growth of cement consumption. This outcome implies that the volume of construction dedicated to infrastructure projects exceeds that of buildings for resident (Fernandez, 2007). The urbanization level utilized in this research refers to the number of permanent inhabitants in the urban area. However, due to the rural-urban dual structure policy, nearly 234 million rural migrants were regarded as urban residents but can't enjoy the urban social welfare, let alone afford a house or even an apartment (Lu et al., 2007; Li, 2011; Wang et al., 2015b). The permanent population encompasses the rural migrants with no urban registration if one lives in cities or towns for more than six months. Obviously, urban demographics have overestimated the urbanization level compared to registered non-agricultural population. Therefore, the actual population urbanization has lagged far behind the excessive fixed investment.

Cement consumption intensity holds the highest regression coefficient (1.0029). But whether the influence on the cement consumption is positive or negative depends on the change of cement consumption intensity. With an increase or decrease of $1 \%$ of the intensity, the dependent variable will increase or decrease $1.0029 \%$ correspondingly. Cement consumption intensity is affected by architectural structure and the technology promotion. Firstly, one of the most important factors determining the use of building cement is architectural structure (Hu et al., 2010a). Since 1990s, China's traditional brick-wood architectural structure has converted into steel-concrete and concrete structure, which claims more cement. Meanwhile, higher construction quality is required to achieve the advanced lifetime expectancy (Hu et al., 2010b). This would also generate more cement consumption in short term. In the two western regions, there is an upward tendency of cement consumption intensity owing to the poor building and infrastructure all long. On the other hand, as the technology improved in some developed region, concrete recently becomes more ecologically friendly with less cement to support a given structural load (Aitcin, 2000). It is obvious that novel cementitious material and green concrete have been applied into the more developed region (i.e., regions located near to the coast) compared to other regions. This has produced some excellent results for promotion of sustainable building construction in the more developed regions (Hu et al., 2010a).

Affluence has a rather prominent positive elasticity effect on the cement consumption. Its elastic coefficient is 0.3016 , implying that every $1 \%$ increase in per capita GDP will give rise to a $0.3016 \%$ increase in cement consumption. It is found that per capita GDP has a significant impact on per capita floor area (Hu et al., 2010b). The income improvement would encourage people to pursue more adequate living space in dwellings.

Population, as third largest elasticity, had a significant positive influence on the cement consumption. Every $1 \%$ increase in population scale will cause a $0.2794 \%$ increase in cement consumption, holding other factors constant. Although China's one child policy has led to a continuous decline in the natural growth rate of China's population, the absolute amount of population increase is still large (Zhao et al., 2014). Population is one of the most important driving forces of demand for building stock (Huang et al., 2013). Therefore, such a large cardinal number of the population would inevitably result in large-scale construction of residential building, commercial facilities and supporting infrastructure, which immediately translated into a rise of cement consumption. Fortunately, the growth of population itself is not significant. 

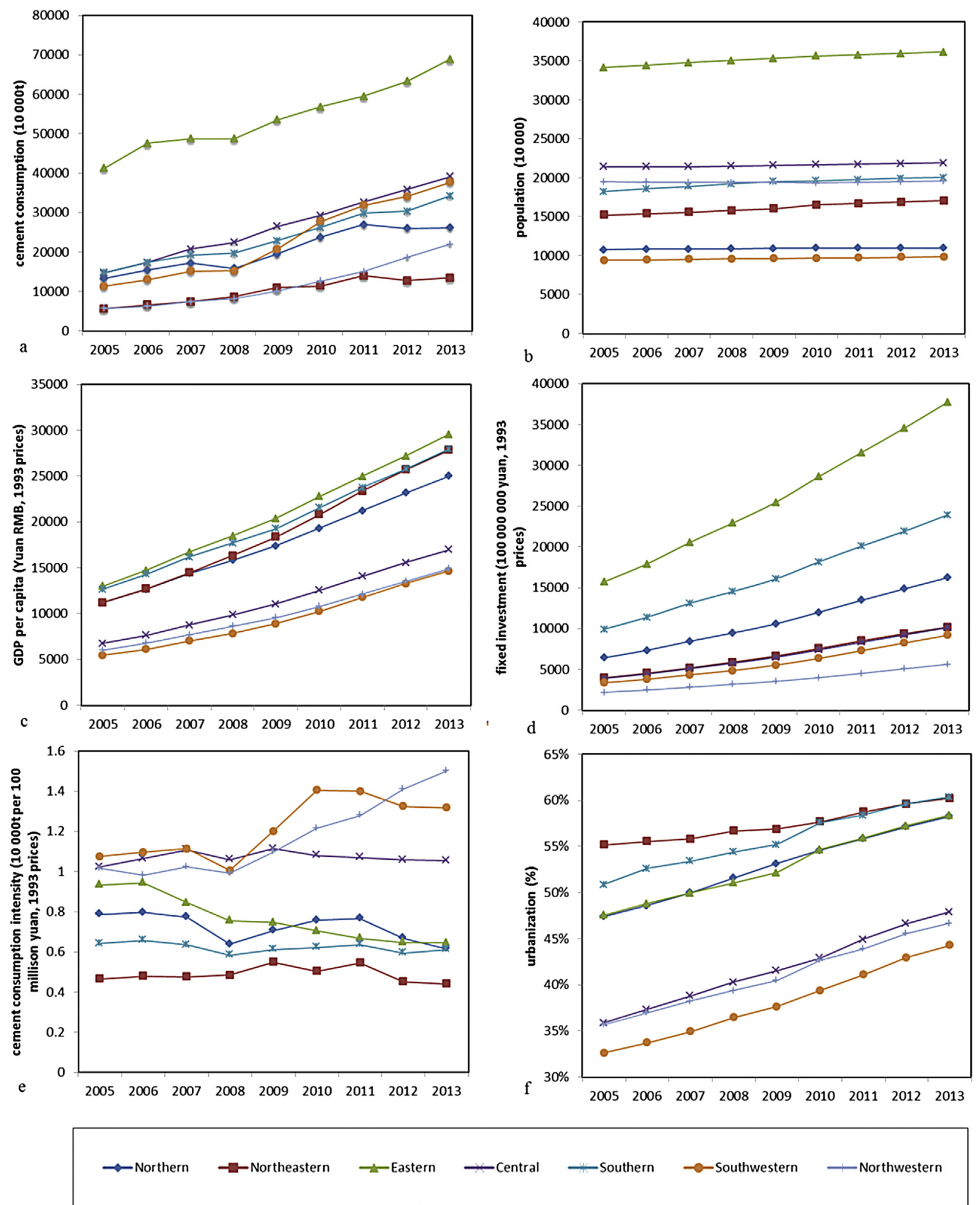

Fig. 2. Description of all variables: (a) Cement consumption, (b) Population, (c) GDP per capita, (d) Fixed investment, (e) Cement consumption intensity, (f) Urbanization.

\subsection{Nonlinear effects of urbanization and affluence}

According to the results derived from Eqs. (4) and (5) in Table 3, the negative signs of GDP per capita and urbanization level confirm the delinking of cement consumption and these two driving forces when at a high level of affluence or urbanization level. The coefficients of the two quadratic terms are both at $1 \%$ level of significance. The coefficient of squared urbanization level is -0.0505 , indicating that a $0.0494 \%$ decline in cement consumption is linked with a 0.01 unit increase of urbanization level. Similarly, a $1 \%$ growth in GDP per capita would cutback the cement consumption by $0.0581 \%$. The nonlinear effects of affluence and urbanization level provide evidence for EKC hypothesis, which are consistent with the previous study (Aitcin, 2000). Generally, 
Table 3

Estimated results of cement consumption during 2005-2013.

\begin{tabular}{|c|c|c|c|c|}
\hline Variables & $\mathrm{FE}$ & TW FE & FGLS (1) & FGLS (2) \\
\hline \multicolumn{5}{|l|}{ Eq. (3) } \\
\hline $\ln P$ & $0.5558^{* * *}(0.0799)$ & $0.3709^{* * *}(0.0698)$ & $0.3232^{* * *}(0.0574)$ & $0.2794^{* * *}(0.0336)$ \\
\hline $\ln A$ & $0.5545^{* * *}(0.0823)$ & $0.4054^{* * *}(0.0556)$ & $0.3278^{* * *}(0.0602)$ & $0.3016^{* * *}(0.0323)$ \\
\hline $\ln T$ & $1.0015^{* * *}(0.0024)$ & $1.0106^{* * *}(0.0021)$ & $1.0024^{* * *}(0.0018)$ & $1.0029^{* * *}(0.0007)$ \\
\hline $\ln F$ & $0.4419^{* * *}(0.0814)$ & $0.4913^{* * *}(0.0454)$ & $0.6331^{* * *}(0.0598)$ & $0.6549^{* * *}(0.0327)$ \\
\hline$U$ & $0.0412(0.0290)$ & $0.0371^{*}(0.0141)$ & $0.0491^{* * *}(0.0141)$ & $0.0445^{* * *}(0.0076)$ \\
\hline$t$ (Time) & & & $0.0040^{* * *}(0.0009)$ & $0.0047^{* * *}(0.0005)$ \\
\hline constant & $-4.6426^{* * *}(0.8240)$ & $-1.9057^{*}(0.8171)$ & $-1.9399^{* * *}(0.6004)$ & $-1.4687^{* * *}(0.3440)$ \\
\hline$R^{2}$ & 0.9899 & & & \\
\hline \multicolumn{5}{|l|}{ Eq. (4) } \\
\hline $\ln P$ & $0.5298^{* * *}(0.0743)$ & $0.3739^{* * *}(0.0685)$ & $0.3279^{* * *}(0.0574)$ & $0.2804^{* * * *}(0.0330)$ \\
\hline $\ln A$ & $0.5777^{* * *}(0.0765)$ & $0.3931^{* * *}(0.0577)$ & $0.3295^{* * *}(0.0611)$ & $0.2918^{* * *}(0.0334)$ \\
\hline $\ln T$ & $1.0064^{* * *}(0.0028)$ & $1.0092^{* * *}(0.0026)$ & $1.0029^{* * *}(0.0020)$ & $1.0030^{* * *}(0.0007)$ \\
\hline $\ln F$ & $0.4158^{* * *}(0.0757)$ & $0.4967^{* * *}(0.0423)$ & $0.6306^{* * *}(0.0600)$ & $0.6614^{* * *}(0.0334)$ \\
\hline$U$ & $-0.1395^{* *}(0.0641)$ & $0.0978(0.0061)$ & $0.0515(0.0490)$ & $0.0828^{* * * *}(0.0225)$ \\
\hline$U^{2}$ & $0.2428^{* * *}(0.0782)$ & $-0.0927(0.0851)$ & $-0.0052(0.0705)$ & $-0.0505^{* * *}(0.0258)$ \\
\hline$t$ (Time) & & & $0.0041^{* * *}(0.0012)$ & $0.0052^{* * *}(0.0005)$ \\
\hline constant & $-4.3441^{* * *}(0.7680)$ & $-1.8779^{*}(0.8432)$ & $-1.9786^{* * *}(0.6011)$ & $-1.4457^{* * *}(0.3402)$ \\
\hline$R^{2}$ & 0.9890 & 0.9824 & & \\
\hline \multicolumn{5}{|l|}{ Eq. (5) } \\
\hline $\ln P$ & $0.5469^{* * *}(0.0774)$ & $0.3758^{* * *}(0.0660)$ & $0.3484^{* * *}(0.0554)$ & $0.2912^{* * *}(0.0288)$ \\
\hline $\ln A$ & $0.4980^{* * *}(0.0840)$ & $0.4292^{* * *}(0.0510)$ & $0.3789^{* * *}(0.0614)$ & $0.3524^{* * *}(0.0262)$ \\
\hline$(\ln A)^{2}$ & $0.0036^{* *}(0.0017)$ & $-0.0013(0.0018)$ & $-0.0021(0.0014)$ & $-0.0030^{* * *}(0.0003)$ \\
\hline $\ln T$ & $1.0052^{* * *}(0.0029)$ & $1.0093^{* * *}(0.0024)$ & $1.0033^{* * *}(0.0020)$ & $1.0030^{* * *}(0.0005)$ \\
\hline $\ln F$ & $0.4282^{* * *}(0.0790)$ & $0.4905^{* * *}(0.0424)$ & $0.6123^{* * *}(0.0578)$ & $0.6492^{* * *}(0.0302)$ \\
\hline$U$ & $0.0666^{* *}(0.0305)$ & $0.0210(0.0199)$ & $0.0200(0.0206)$ & $0.0138^{* *}(0.0059)$ \\
\hline$t$ (Time) & & & $0.0055^{* * *}(0.0012)$ & $0.0065^{* * *}(0.0003)$ \\
\hline constant & $-4.2316^{* * *}(0.8205)$ & $-2.0467^{* *}(0.7292)$ & $-2.2801^{* * *}(0.5873)$ & $-1.7285^{* * *}(0.2762)$ \\
\hline \multicolumn{5}{|c|}{$-4.2510 \quad(0.0200)$} \\
\hline Observation & 378 & 378 & 378 & 378 \\
\hline
\end{tabular}

Note: ${ }^{*} \mathrm{p}<0.1,{ }^{* *} \mathrm{p}<0.05,{ }^{* * *} \mathrm{p}<0.01$.

cement consumption of a country starts to decline after the saturation point. Notwithstanding, it should be pointed out that China still hasn't reached the saturation point of cement consumption.

\subsection{Regional effects}

As demonstrated in Table 4, the estimation results of the three equations are similar and the regression results of regional variables are significant at $1 \%$ level. According to the results from Eq. (3), the coefficients of regional variables can be ranked in descending order as follows: Central (0.1571), Eastern (0.0388), Southwestern (0.0376), Northern $(-0.0678)$, Southern $(-0.1310)$, Northwestern $(-0.1314)$. The regression coefficients of dummy variables demonstrate that the cement consumption varies widely from region to region, even controlling the other variables. The coefficients cannot be interpreted as elasticity coefficients. As shown in Table 4, the coefficient of the dummy variable for the eastern region is 0.0388 , providing an interpretation relative to the base region. It is indicated that even at the same level of population, GDP per capita, cement consumption intensity, fixed investment and urbanization, the cement consumption of northern region is 1.0396 -fold (i.e., $\mathrm{e}^{0.0388}$ ) higher than that of the northeastern region. In another word, cement consumption of eastern region is $3.96 \%$ higher than that of the base region. China is vast in territory, with different geographic, climate and resource endowments (Zhang and Lin, 2012). First, the thermal design of building in different regions is in accordance with the building thermal design zoning, which determines the cement consumption of buildings in different regions. Second, the cement dosage in infrastructure construction, especially in transportation construction, is also in compliance with the natural conditions in different regions (Yang, 1964).

\subsection{Contribution of driving factors}

The contribution of the driving forces to cement consumption is given in Table 5 . The result manifests that fixed investment and GDP per capita are the two main driving forces of cement consumption because both of two factors have a phenomenal growth rate. From 2005 to 2013, fixed investment and GDP per capita in China increases by $16.43 \%$ and $15.14 \%$ per annum, leading to $10.76 \%$ and $4.57 \%$ increase of cement consumption with contribution

Table 4

Coefficients of regional variables.

\begin{tabular}{lrr}
\hline Regional variables & Eq. $(3)$ & Eq. $(4)$ \\
\hline Region 2 & $-0.0678^{* * *}(0.0049)$ & $-0.0726^{* * *}(0.0056)$ \\
Region 3 & $0.0388^{* * *}(0.0090)$ & $0.0293^{* * *}(0.0095)$ \\
Region 4 & $-0.1310^{* * *}(0.0095)$ & $-0.0719^{* * *}(0.0047)$ \\
Region 5 & $0.1571^{* * *}(0.0086)$ & $0.0322^{* * * *}(0.0063)$ \\
Region 6 & $-0.1314^{* * *}(0.0055)$ & $-0.1499^{* * *}(0.0081)$ \\
Region 7 & $0.0376^{* * *}(0.0045)$ & $-0.1352^{* * *}(0.0057)$ \\
\hline
\end{tabular}

Note: The northeastern region is the base region (i.e. Region 1). Region 2-7 refer to Northern, Eastern, Southern, Central, Northwestern and Southwestern, respectively. ${ }^{*} \mathrm{p}<0.1,{ }^{* *} \mathrm{p}<0.05,{ }^{* * *} \mathrm{p}<0.01$. 
Table 5

Contributions of the driving forces in the growth of cement consumption.

\begin{tabular}{|c|c|c|c|c|c|}
\hline Variables & Total growth rate $(\%)$ & $\begin{array}{l}\text { Average annual } \\
\text { growth rate (\%) }\end{array}$ & $\begin{array}{l}\text { Regression } \\
\text { coefficient }\end{array}$ & $\begin{array}{l}\text { Effect on the change of } \\
\text { cement consumption (\%) }\end{array}$ & $\begin{array}{l}\text { Contribution degree to change } \\
\text { of cement consumption (\%) }\end{array}$ \\
\hline Cement consumption & 126.05 & 14.01 & & & \\
\hline Population & 5.37 & 0.60 & 0.2794 & 0.17 & 1.19 \\
\hline GDP per capita & 136.26 & 15.14 & 0.3016 & 4.57 & 32.60 \\
\hline Cement consumption intensity & -9.25 & -1.03 & 1.0029 & -1.03 & -7.36 \\
\hline Urbanization $^{1}$ & 0.11 & 0.01 & 0.0445 & 0.05 & 0.38 \\
\hline Fixed investment & 147.83 & 16.43 & 0.6549 & 10.76 & 76.81 \\
\hline Other factors & & & & -0.51 & -3.62 \\
\hline
\end{tabular}

Note: 1.Urbanization growth is measured by absolute value.

degree of $76.81 \%$ and $32.60 \%$, respectively. The regression coefficient of cement consumption intensity is approximately $40 \%$ larger than that of fixed investment. Nonetheless, the impact of cement consumption intensity is rather small which results in a decrease of $1.03 \%$ with a contribution degree of $-7.36 \%$. Population and urbanization have little effect on cement consumption growth with contribution rate of $1.19 \%$ and $0.38 \%$, respectively.

\section{Conclusions and policy implications}

\subsection{Conclusions}

Using STIRPAT model, we examined the linear, nonlinear and regional effects of the driving factors on cement consumption in China during the period of 2005-2013. The statistical significance of empirical results permitted ones to come to the following conclusions.

(1) Although the population urbanization kept growing at a certain rate, its influence and contribution on cement consumption was rather small. Meanwhile, fixed investment had the greatest positive impact on the increase of cement consumption.

(2) The elasticity of GDP per capita was rather pronounced, which contributed to a high degree of cement consumption growth ranked after fixed investment.

(3) The elasticity for population was slightly lower than GDP per capita, however, exerted considerably insignificant influence on cement consumption due to population's moderate growth.

(4) Cement consumption per GDP, provided the highest elasticity and was the unique negative influential factor that offset the increase of cement consumption.

(5) The negative sign for quadratic terms of GDP per capita and urbanization level suggested that the nonlinear effects of these two factors tended to neutralize the linear effects of them.

(6) Due to China's huge size, the material content of building and infrastructure in different regions would significantly affect the required amount of cements.

\subsection{Policy implications}

In terms of policy, these results not only contribute to the existing literature, but also deserve particular attentions from urban planners and policy makers in China.

One of the defining features of China's growth has been investment-led growth (Sahoo et al., 2010). Previous urbanization policies focused on the infrastructure and ignored the inequity among the non-urban registration migrants and urban registration residents. The new-type urbanization should provide more welfare housing for the migrants. Currently, the achievement of local government is evaluated by economic growth, which is stimulated by enormous fixed investment. China's urbanization speed has deviated from the principle of gradual and orderly progress (Lu et al., 2007), and rigorous demand on cement has been pre-consumed. Therefore, only when the excessive fixed investment is curbed does the enthusiasm of cement consumption calm down.

It is highly likely that China will maintain its rapid economic growth. The only way forward for China is to alter its resource and environmental policies so as to sustain its future urbanization and modernization (Shen et al., 2005). Therefore, green building material and resource-saving concepts should be advocated, which further lead to less cement consumption as well as other nonrenewable resources. Green building is to reduce the use of natural resources within one building by virtue of energy-efficient appliances and control systems. Green building materials encompass environmental-friendly products such as recycled carpets, natural linoleum and bamboo flooring (Wang et al., 2013b). A key stipulation to mitigate the cement consumption in the construction industry is to restrict the maximum floor area of the large apartment and encourage appropriate housing space. In a word, China's government should change its focus from pursuing economic growth to sustainable development.

China's population is large in size and always a persistent driving force influencing the consumption of any resources. In fact, the Family Planning policy, known as One Child Policy, has distorted sex ratios at birth and created a range of societal problems (Lin et al., 2009). Subsequently, increasing numbers of couples will be solely responsible for the care of one child and two parents (Hesketh et al., 2005). Hence, the population-control measure should not be implemented as the solution for reducing cement consumption. Alternative solutions have to be explored to alleviate the accelerated cement consumption.

Since the growth of cement consumption intensity is not significant, there is great potential to reduce the cement consumption. Considering the other driving forces will continue to grow, measures to improve the technology are essential. First, an urgent measure is to develop innovative architectural concepts and structural designs to minimize consumption of concrete. Second, blending one or more complementary cementitious materials into concrete is another effective way to save cement consumption. A high-volume fly ash concrete provides the most promising example of how people can build a concrete structure that is more durable and cement-efficient than conventional concrete (Mehta, 2002). Third, in the long run, lengthening the service life of newly built structure can reduce the cement consumption in the construction industry because durable building or infrastructure will require fewer inputs for repair and maintenance and result in less demand for cement. Finally, a holistic building design and technology is required, as well as the participation of researchers. Moreover, it is imperative to establish resource-saving and incentive policy by both of China's central and local government. 
When formulating policy, the disparities of regions should not be neglected. It is important to bear in mind that regional differences arise naturally in geography and in natural endowment. China's sustainable development is now confronting the gap of resources utility efficiency between developed regions and subdeveloped regions. Though it is of critical importance to continue providing infrastructure in less-developed regions (Démurger et al., 2002), an extensive investment of construction is no longer suitable in consideration of sustainable development in these areas. In the foreseen future, the promotion of green strategy in these regions will have a significant contribution to the implementation of sustainable development in China (Zhang et al., 2011). The empirical result also roughly depicts the interregional disparities of cement consumption. It is the diverse construction standards that make a difference of cement consumption in each area. However, the specific determinants of the disparities haven't been revealed. The regional input-output analysis is a recommended instrument to locate the reasons (e.g., final demand structure, industrial structure and technical efficiency) for the regional disparities of cement consumption. This paper only provides a primary interpretation of the regional disparity. An explicit investigation of regional disparities is left for future research.

In summarize, the mainsprings for the surging cement consumption in China during the urbanization process from 2005 to 2011 are excessive infrastructure and the improvement of income level. Consumption of cement is expected to grow if without appropriate reorientation for urbanization pathway. To achieve sustainable economic growth, it is indispensable for Chinese policy makers to design a growth strategy that improves the physical infrastructure and resource efficiency as well as the equity between urban and rural. Firstly, integration policy of urban-rural should be put forward to reduce the gap between urban household residents and rural household residents. Secondly, improvement of interest rate marketization will rectify the irrational investment in infrastructure. Furthermore, guidance of green construction should be promoted by the government, for instance, on-site recycling, alternative construction material, favorable tax policy (Zhang et al., 2011). Overall, the priority development policy in the future should be intensive and sustainable.

\section{Acknowledgment}

This work was financially supported by the Strategic Priority Research Program - Climate Change: Carbon Budget and Related Issues of the Chinese Academy of Sciences (Grant No. XDA05 010400) and the National Natural Science Foundation of China (Grant NO. 41271547, 41401644, 41501604). The authors thank all anonymous reviewers for their valuable comments and suggestion.

\section{References}

Aïtcin, P.C., 2000. Cements of yesterday and today: concrete of tomorrow. Cem. Concr. Res. 30 (9), 1349-1359.

Ali, M.B., Saidur, R., Hossain, M.S., 2011. A review on emission analysis in cement industries. Renew. Sustain. Energy Rev. 15 (5), 2252-2261.

Ang, B.W., Zhang, F.Q., 2000. A survey of index decomposition analysis in energy and environmental studies. Energy 25 (12), 1149-1176.

CCA, China Cement Association, 2012. China Cement Almanac 2011. China Building Material Industry Publishing House, Beijing (In Chinese).

Chen, M., Liu, W., Tao, X., 2013. Evolution and assessment on China's urbanization 1960-2010: under-urbanization or over-urbanization? Habitat Int. 38, 25-33.

CLCRC, China Lianhe Credit Rating Co.,Ltd, 2013. China's Cement Industry Research Report: 2013 (In Chinese).

Démurger, S., Sachs, J.D., Woo, W.T., Bao, S., Chang, G., Mellinger, A., 2002. Geography, economic policy, and regional development in china. Asian Econ. Pap. 1 (1), 146-197.

Dietz, T., Rosa, E.A., 1994. Rethinking the environmental impacts of population, affluence and technology. Hum. Ecol. Rev. 1, 277-300.
Ehrlich, P.R., Holdren, J.P., 1971. Impact of population growth. Science 171 (3977), $1212-1217$.

Fan, Y., Liu, L.C., Wu, G., Wei, Y.M., 2006. Analyzing impact factors of $\mathrm{CO}_{2}$ emissions using the STIRPAT model. Environ. Impact Assess. Rev. 26 (4), 377-395.

Fernandez, J.E., 2007. Resource consumption of new urban construction in China. J. Ind. Ecol. 11 (2), 99-115.

Greene, W.H., 2000. Econometric Analysis, fourth ed. Prentice Hall, Upper Saddle River: New Jersey.

Guan, D., Hubacek, K., Weber, C.L., Peters, G.P., Reiner, D.M., 2008. The drivers of Chinese $\mathrm{CO}_{2}$ emissions from 1980 to 2030. Glob. Environ. Change 18 (4), 626-634.

Guo, Z., Hu, D., Zhang, F., Huang, G., Xiao, Q., 2014. An integrated material metabolism model for stocks of urban road system in Beijing, China. Sci. Total Environ. 470, 883-894.

Hesketh, T., Lu, L., Xing, Z.W., 2005. The effect of China's one-child family policy after 25 years. N. Engl. J. Med. 353 (11), 1171-1176.

Hirschnitz-Garbers, M., Tan, A.R., Gradmann, A., Srebotnjak, T., 2015. Key drivers for unsustainable resource use-categories, effects and policy pointers. J. Clean. Prod.

Hu, D., You, F., Zhao, Y., Yuan, Y., Liu, T., Cao, A., Wang, Z., Zhang, J., 2010a. Input, stocks and output flows of urban residential building system in Beijing city, China from 1949 to 2008. Resour. Conserv. Recycl. 54 (12), 1177-1188.

Hu, M., Bergsdal, H., van der Voet, E., Huppes, G., Müller, D.B., 2010b. Dynamics of urban and rural housing stocks in China. Build. Res. Inf. 38 (3), 301-317.

Huang, T., Shi, F., Tanikawa, H., Fei, J., Han, J., 2013. Materials demand and environmental impact of buildings construction and demolition in China based on dynamic material flow analysis. Resour. Conserv. Recycl. 72, 91-101.

Ji, X., Chen, B., 2015. Assessing the energy-saving effect of urbanization in China based on stochastic impacts by regression on population, affluence and technology (STIRPAT) model. J. Clean. Prod.

Jia, J., Deng, H., Duan, J., Zhao, J., 2009. Analysis of the major drivers of the ecological footprint using the STIRPAT model and the PLS method-a case study in Henan Province, China. Ecol. Econ. 68 (11), 2818-2824.

Ke, J., Zheng, N., Fridley, D., Price, L., Zhou, N., 2012. Potential energy savings and $\mathrm{CO}_{2}$ emissions reduction of China's cement industry. Energy Policy 45, 739-751.

Krausmann, F., Gingrich, S., Eisenmenger, N., Erb, K.H., Haberl, H., FischerKowalski, M., 2009. Growth in global materials use, GDP and population during the 20th century. Ecol. Econ. 68 (10), 2696-2705.

Lei, Y., Zhang, Q., Nielsen, C., He, K., 2011. An inventory of primary air pollutants and $\mathrm{CO}_{2}$ emissions from cement production in China, 1990-2020. Atmos. Environ. 45 (1), 147-154.

Li, Y., 2011. The complexity of urban transformation in China: new trends in current transitional era. J. ITU Fac. Archit. 8 (1), 155-168.

Liddle, B., Lung, S., 2010. Age-structure, urbanization, and climate change in developed countries: revisiting STIRPAT for disaggregated population and consumption-related environmental impacts. Popul. Environ. 31 (5), 317-343.

Lin, S., Zhao, D., Marinova, D., 2009. Analysis of the environmental impact of China based on STIRPAT model. Environ. Impact Assess. Rev. 29 (6), 341-347.

Liu, L.C., Fan, Y., Wu, G., Wei, Y.M., 2007. Using LMDI method to analyze the change of China's industrial $\mathrm{CO}_{2}$ emissions from final fuel use: an empirical analysis. Energy Policy 35 (11), 5892-5900.

Liu, Y., Xiao, H., Lv, Y., Zhang, N., 2015. The effect of new-type urbanization on energy consumption in China: a spatial econometric analysis. J. Clean. Prod.

Lu, D.D., Yao, S.M., Li, G.P., Liu, H., GAO, X.L., 2007. Comprehensive analysis of the urbanization process based on China's conditions. Econ. Geogr. 6, 002 (In Chinese).

Mehta, P.K., 2002. Greening of the concrete industry for sustainable development. Concr. Int. 23.

Müller, D.B., 2006. Stock dynamics for forecasting material flows-case study for housing in The Netherlands. Ecol. Econ. 59 (1), 142-156.

NBSC, National Bureau of Statistics of China, 2014. China Statistical Yearbook. China Statistics Press, Beijing.

Pesaran, M.H., 2004. General Diagnostic Tests for Cross Section Dependence in Panels. Cambridge Working Papers in Economics, 0435. University of Cambridge.

Rodrigues, F.A., Joekes, I., 2011. Cement industry: sustainability, challenges and perspectives. Environ. Chem. Lett. 9 (2), 151-166.

Sahoo, P., Dash, R.K., Nataraj, G., 2010. Infrastructure Development and Economic Growth in China.

Shahbaz, M., Loganathan, N., Muzaffar, A.T., Ahmed, K., Jabran, M.A., 2016. How urbanization affects $\mathrm{CO}_{2}$ emissions in Malaysia? the application of STIRPAT model. Renew. Sustain. Energy Rev. 57, 83-93.

Shen, L., Cheng, S., Gunson, A.J., Wan, H., 2005. Urbanization, sustainability and the utilization of energy and mineral resources in China. Cities 22 (4), 287-302.

Shen, L., Gao, T., Zhao, J., Wang, L., Wang, L., Liu, L., Chen, F., Xue, J., 2014. Factorylevel measurements on $\mathrm{CO}_{2}$ emission factors of cement production in China. Renew. Sustain. Energy Rev. 34, 337-349.

Uwasu, M., Hara, K., Yabar, H., Zhang, H., 2012. Scenario analysis of cement production in China: the role of policy and technology in the pathway to sustainable society. In: Design for Innovative Value towards a Sustainable Society. Springer Netherlands.

Waggoner, P.E., Ausubel, J.H., 2002. A framework for sustainability science: a renovated IPAT identity. Proc. Natl. Acad. Sci. 99 (12), 7860-7865.

Wang, P., Wu, W., Zhu, B., Wei, Y., 2013a. Examining the impact factors of energyrelated $\mathrm{CO}_{2}$ emissions using the STIRPAT model in Guangdong Province, China. Appl. Energy 106, 65-71.

Wang, T., Tian, X., Hashimoto, S., Tanikawa, H., 2015a. Concrete transformation of buildings in China and implications for the steel cycle. Resour. Conserv. Recycl. 103, 205-215. 
Wang, W., Jiang, D., Chen, D., Chen, Z., Zhou, W., Zhu, B., 2016. A Material Flow Analysis (MFA)-based potential analysis of eco-efficiency indicators of China's cement and cement-based materials industry. J. Clean. Prod. 112, 787-796.

Wang, X.R., Hui, E.C.M., Choguill, C., Jia, S.H., 2015b. The new urbanization policy in China: which way forward? Habitat Int. 47, 279-284.

Wang, Y., Höller, S., Viebahn, P., Hao, Z., 2014. Integrated assessment of $\mathrm{CO}_{2}$ reduction technologies in China's cement industry. Int. J. Greenh. Gas Control 20, 27-36.

Wang, Y., Zhu, Q., Geng, Y., 2013b. Trajectory and driving factors for GHG emissions in the Chinese cement industry. J. Clean. Prod. 53, 252-260.

Wen, Z., Chen, M., Meng, F., 2015. Evaluation of energy saving potential in China's cement industry using the Asian-Pacific Integrated Model and the technology promotion policy analysis. Energy Policy 77, 227-237.

Wooldridge, J.M., 2000. Econometric Analysis of Cross Section and Panel Data. MIT Press.

Woodward, R., Duffy, N., 2011. Cement and concrete flow analysis in a rapidly expanding economy: Ireland as a case study. Resour. Conserv. Recycl. 55 (4), 448-455.

Xu, J.H., Fleiter, T., Eichhammer, W., Fan, Y., 2012. Energy consumption and $\mathrm{CO}_{2}$ emissions in China's cement industry: a perspective from LMDI decomposition analysis. Energy Policy 50, 821-832.

Xu, J.H., Fleiter, T., Fan, Y., Eichhammer, W., 2014. $\mathrm{CO}_{2}$ emissions reduction potential in China's cement industry compared to IEA's Cement Technology Roadmap up to 2050. Appl. Energy 130, 592-602.
Yang, W.Y., 1964. The evaluation and zoning profile of traffic natural condition in China. Acta Geogr. Sin. 30 (4), 301-319 (In Chinese).

York, R., Rosa, E.A., Dietz, T., 2003. STIRPAT, IPAT and ImPACT: analytic tools for unpacking the driving forces of environmental impacts. Ecol. Econ. 46 (3), $351-365$.

York, R. 2007. Demographic trends and energy consumption in European Union Nations, 1960-2025. Soc. Sci. Res. 36 (3), 855-872.

Zha, D., Zhou, D., Zhou, P., 2010. Driving forces of residential $\mathrm{CO}_{2}$ emissions in urban and rural China: an index decomposition analysis. Energy Policy 38 (7), 3377-3383.

Zhang, C., Lin, Y., 2012. Panel estimation for urbanization, energy consumption and $\mathrm{CO}_{2}$ emissions: a regional analysis in China. Energy Policy 49, $488-498$.

Zhang, X., Shen, L., Wu, Y., 2011. Green strategy for gaining competitive advantage in housing development: a China study. J. Clean. Prod. 19 (2), 157-167.

Zhao, C., Chen, B., Hayat, T., Alsaedi, A., Ahmad, B., 2014. Driving force analysis of water footprint change based on extended STIRPAT model: evidence from the Chinese agricultural sector. Ecol. Indic. 47, 43-49.

Zhu, B., Jiang, D., Chen, D., Li, Q., Wang, W., 2014. SFA-based resources consumption analysis on China's cement and cement-based materials industry. J. Tsinghua Univ. Sci. Technol. 54 (7), 839-845 (In Chinese). 